\title{
A Comparative Evaluation of the Marginal and Internal Fit of Laboratory-fabricated Monolithic Zirconia Crowns using Direct and Indirect Methods of Scanning: An in vitro Study
}

\author{
${ }^{1}$ Kushal N Gandhi, ${ }^{2}$ Sabita M Ram
}

\begin{abstract}
Aim: To evaluate the marginal and internal fit of laboratoryfabricated monolithic zirconia crowns using direct and indirect methods of scanning.

Materials and methods: A stainless steel master model was selected, which included stainless steel die, outer cap, and inner cap. The study was divided into two groups. In group I, direct method of scanning was carried out in which the stainless steel die was scanned directly with chairside scanner, and in group II, impression of the stainless steel die was made and gypsum die was fabricated, which was then subjected to scanning. Zirconia blanks or blocks were milled, sintered, and polished to obtain 10 zirconia crowns of each group. Replica technique was used to evaluate fit of crowns by using light body as cement analog. The crowns were then sectioned, viewed under a stereomicroscope, and each predetermined region was measured and evaluated for marginal and internal fit.
\end{abstract}

Results: The descriptive statistics showed that the mean marginal fit for indirect method was higher compared with that for direct method. The results of paired-sample t-test revealed that mean marginal and internal fit for indirect method was on the upper side of the scale, whereas the mean for the direct method is on the lower side of the scale. Thus, the difference in the means of two methods was quite large and likely to be significant.

Conclusion: The results did show better marginal and internal fit in crowns fabricated by the direct method; however, the crowns fabricated by the indirect method had more discrepancy, but were in the clinically acceptable limit.

Clinical significance: The present study would serve as a useful guide in deciding which method of scanning would give a better marginal and internal fit of monolithic zirconia crowns for longevity of restorations.

Keywords: Computer-aided design/computer-aided manufacturing, Monolithic, Replica technique.

How to cite this article: Gandhi KN, Ram SM. A Comparative Evaluation of the Marginal and Internal Fit of

\footnotetext{
${ }^{1}$ Prosthodontist, ${ }^{2}$ Dean, Professor and Head

1,2Department of Prosthodontics and Crown \& Bridge, Mahatma Gandhi Mission's Dental College and Hospital, Mumbai Maharashtra, India

Corresponding Author: Kushal N Gandhi, Prosthodontist Department of Prosthodontics and Crown \& Bridge, Mahatma Gandhi's Mission Dental College and Hospital, Mumbai Maharashtra, India, Phone: +91-9819235890, e-mail: drkushalng9 @gmail.com
}

Laboratory-fabricated Monolithic Zirconia Crowns using Direct and Indirect Methods of Scanning: An in vitro Study. J Contemp Dent 2017;7(1):22-27.

Source of support: Dental Ceramists Pvt. Ltd., Pradhan Dental Centre

\section{Conflict of interest: None}

\section{INTRODUCTION}

The aim of prosthodontics is to replace missing teeth and restore those that are mutilated. The restorations should fit accurately, have the desired form, and fulfill esthetic and functional requirements. Success of fixed restorations depends to a large extent on the fit between restorations and prepared tooth structure. Fabrication of restorations by the conventional lost wax technique is influenced by the dimensional properties of wax, investment material, and the casting alloy used. The casted restorations may have imperfections due to the porosities or corrosionprone mixed crystals. ${ }^{1}$

Restorations can be fabricated by the computer-aided design/computer-aided manufacturing (CAD/CAM) technology in which they are milled from blocks of base metal alloy, ceramic, zirconia, or resin as an alternative to the conventional lost wax technique.

The major developments of dental CAD/CAM systems occurred in the 1980s. There were three pioneers, in particular, who contributed to the development of the current dental CAD/CAM system - Duret and Preston, ${ }^{2}$ Mörmann et al, ${ }^{3}$ and Andersson and Oden. ${ }^{4}$

The present CAD/CAM technology requires acquisition of data, which is done by digitalized mechanical scanning. The scanners could be optical, laser, or contact scanners utilized for this purpose. It has been reported that optical scanners showed minimum marginal discrepancy as compared with contact and laser scanners. ${ }^{5}$ The accepted marginal opening between 100 and $150 \mu \mathrm{m}$ was considered clinically acceptable with regard to the success of the restorations. ${ }^{6-9}$ Restorations not having a proper fit may reduce longevity due to increased dissolution of the luting cement, leading to ingress of microorganism and periodontal tissue inflammation. ${ }^{10,11}$

Zirconia is available for fabrication of restoration in its presintered form and fully sintered form, and is available 


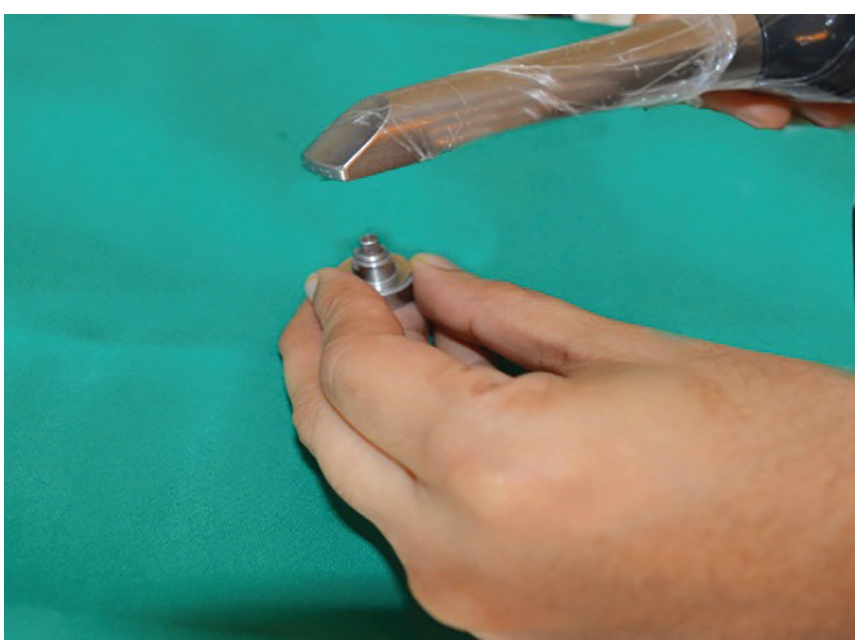

Fig. 1: Direct scanning of master die

in blocks or blanks. It is easy to mill the presintered zirconia and later sinter it to achieve the final restoration, using CAD/CAM technology.

The marginal and internal fits of zirconia restorations fabricated by CAD/CAM technology are better as compared with the restorations fabricated by the lost wax technique.

This study was, therefore, planned to evaluate the marginal and internal fits of laboratory-fabricated zirconia crowns by direct chairside method of scanning and indirect method of scanning.

\section{MATERIALS AND METHODS}

A stainless steel master model was selected, which included master die simulating prepared premolar with $4.5 \mathrm{~mm}$ height, $6^{\circ}$ taper, and $120^{\circ}$ chamfer as finish line, with customized outer cap $3 \mathrm{~mm}$ in thickness simulating the custom tray and inner cap $2 \mathrm{~mm}$ in thickness simulating the spacer.

The study was divided into two groups: In group I, direct method of scanning was done using chairside direct scanner (APOLLO DI, SIRONA) (Fig. 1) in which master die was powdered and scanned to obtain threedimensional (3D) images of the master die on the computer attached to the scanner. The finish line was obtained and $40 \mu \mathrm{m}$ spacer was used to fabricate the crowns. The coping followed by the superstructure of first premolar was virtually designed, and zirconia blocks were subjected to milling, sintering, and glazing of crowns.

Following the same procedure, the master die was powdered and scanned another nine times, and the powder layer from the master die was removed by steam at every scan and renewed before each scan was done, followed by virtual designing of crowns, and then the blocks were subjected to milling, sintering, and glazing to obtain a total of 10 monolithic zirconia crowns (Fig. 2).

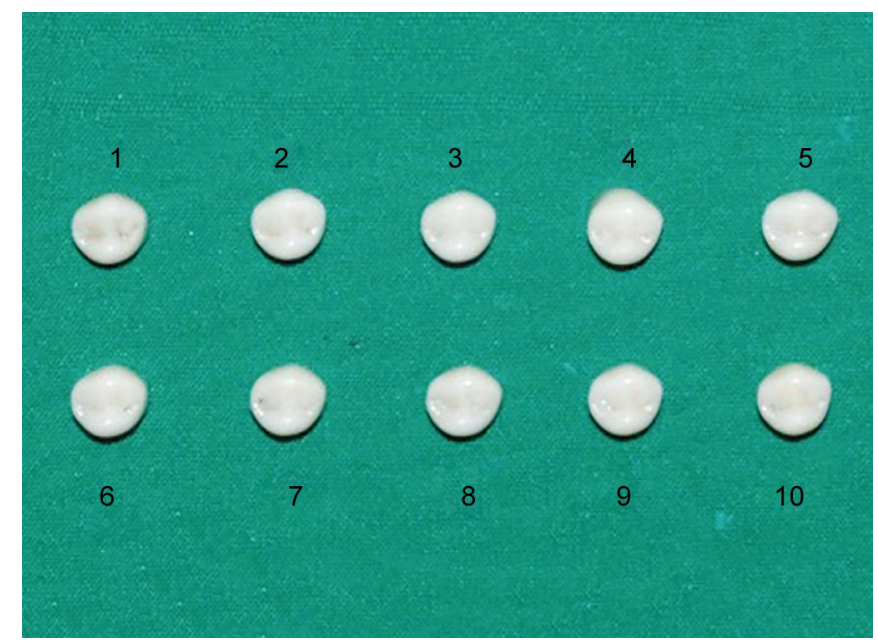

Fig. 2: Monolithic zirconia crowns - group I

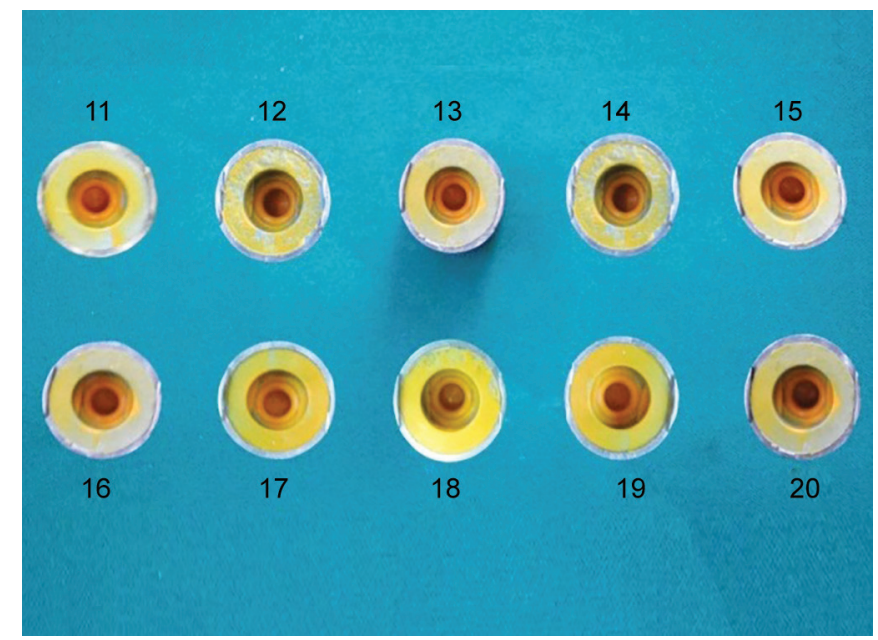

Fig. 3: Impressions of master die - group II

In group II, indirect method of scanning was carried out. In this, two-stage impression technique of the master die was made (Fig. 3), and the impression obtained was poured in type IV gypsum with standardized water powder ratio to obtain a gypsum die (Fig. 4), which was then subjected to scanning. Scanning was carried out using indirect scanner CAD/CAM unit LAVA $^{\mathrm{TM}}$ SCAN ST Design system, 3M ESPE) (Fig. 5) and 3D image was obtained, which was virtually designed. Finish line was obtained and $40 \mu \mathrm{m}$ spacer was used to fabricate the crowns. The coping followed by superstructure of first premolar was virtually designed and obtained from the software.

Following the same procedure, another nine type IV gypsum dies were scanned and virtual designing of crowns was done to mill the zirconia to obtain a total of 10 monolithic zirconia crowns (Fig. 6). Thus, 10 wellpolished monolithic zirconia crowns were obtained for each group and numbered 1 to 10 for group I and 11 to 20 for group II for identification. 


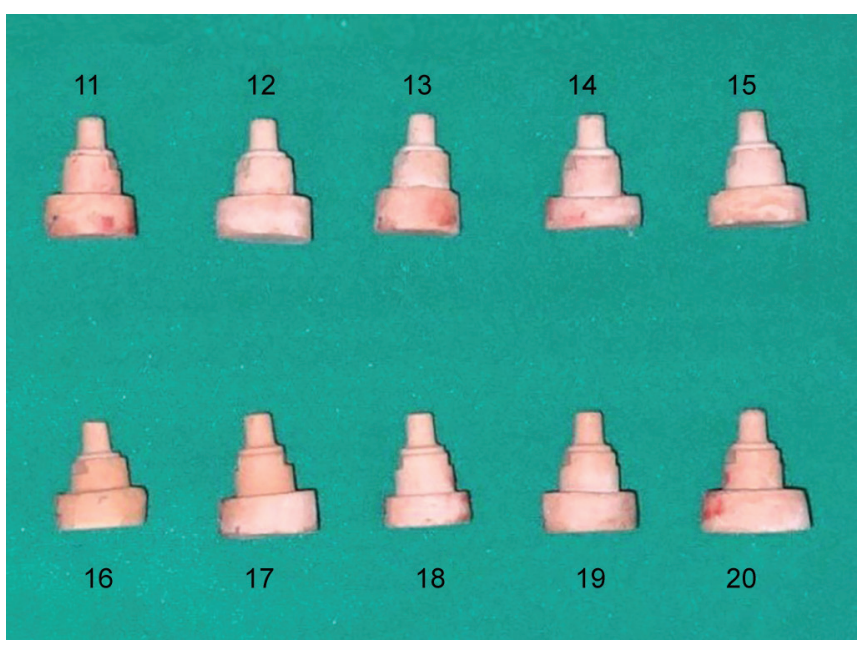

Fig. 4: Type IV gypsum dies - group II

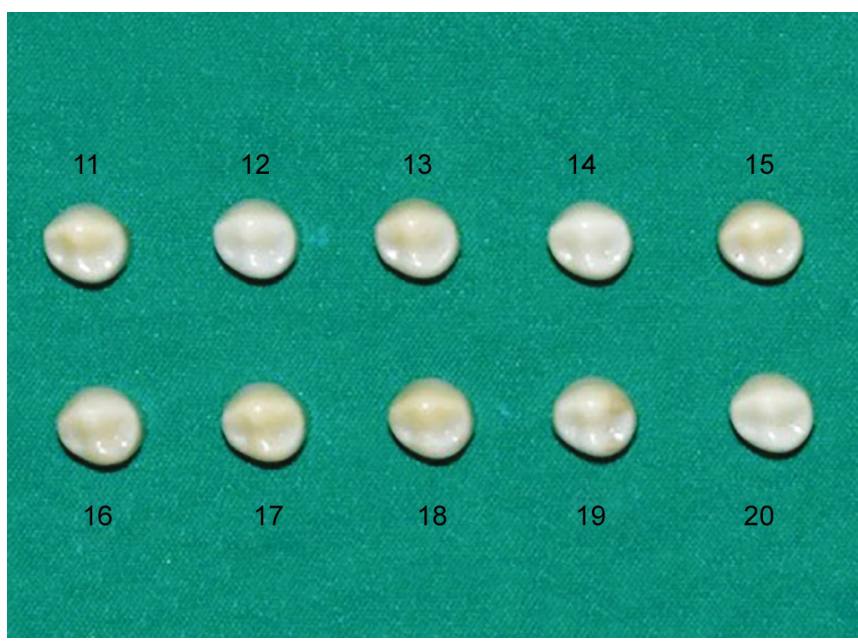

Fig. 6: Monolithic zirconia crowns - group II

\section{Evaluation of Marginal and Internal Fit}

The marginal and internal adaptations of all monolithic zirconia crowns were evaluated using the replica technique. In this technique, vinyl polysiloxane impression

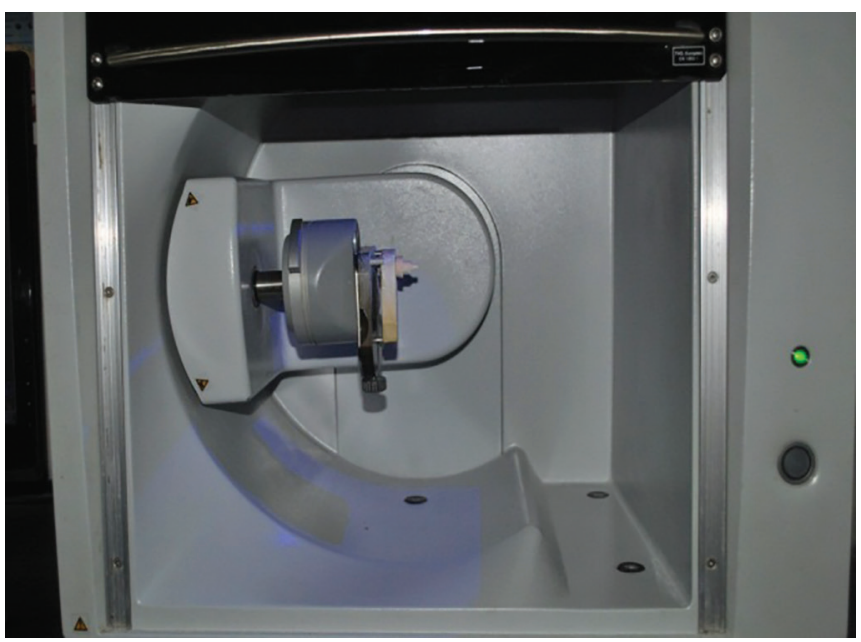

Fig. 5: Indirect scanning of type IV gypsum die

material - light body [FLEXCEED (GC)] was used as the cement analog. A load of $20 \mathrm{~N}$ was applied to the occlusal surface of monolithic zirconia crown for 5 minutes while they were in the Instron testing machine for standardization of procedure. ${ }^{12}$

After the light body silicone had set, monolithic zirconia crowns containing the light body were removed from the master die and the space occupied by the master die was filled with type IV gypsum following standardized procedure.

Similarly, remaining zirconia crowns numbering 2 to 20 of groups I and II were subjected to occlusal load one after the other in Instron testing machine and removed from the master die after light body had set. In a similar standardized manner, the samples 2 to 20 were poured with type IV gypsum, in the space occupied by the master die which were numbered 2 to 20 (Figs 7A and B).

\section{Sectioning of Crowns}

A DFS diamond disk (DIAMON) was used to cut the monolithic zirconia crowns in the occlusal-gingival
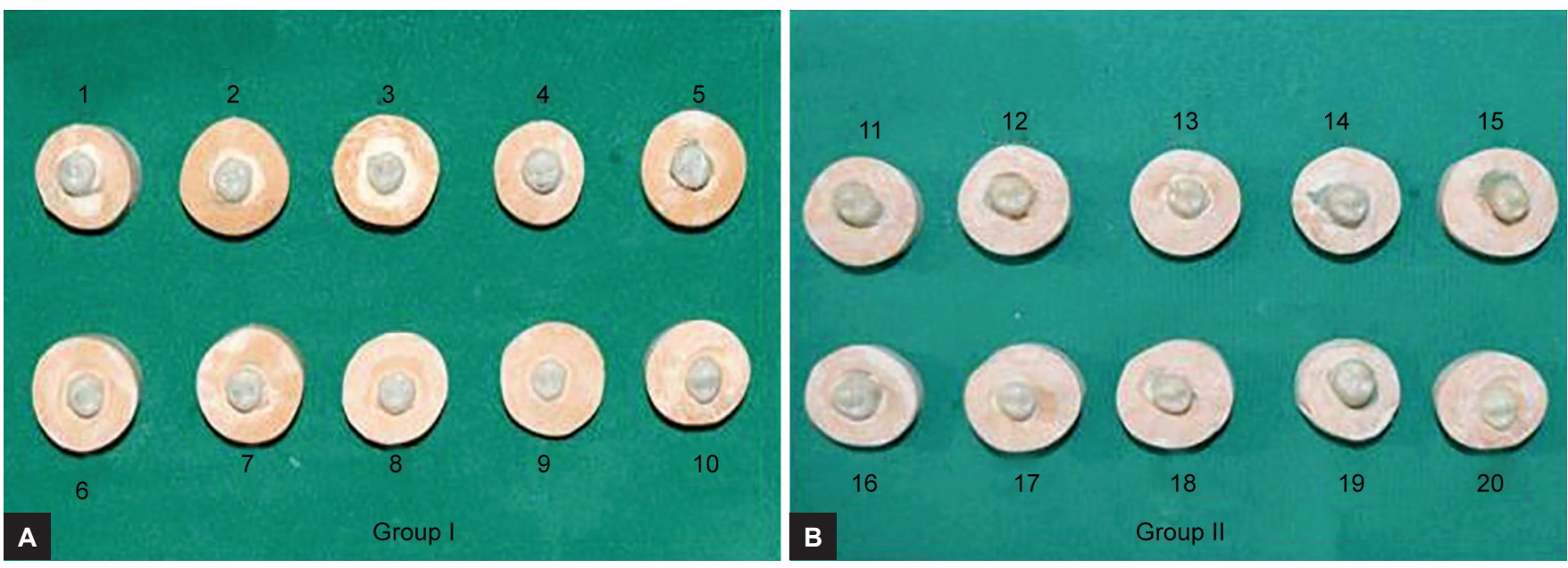

Figs 7A and B: Zirconia crowns mounted in type IV gypsum 


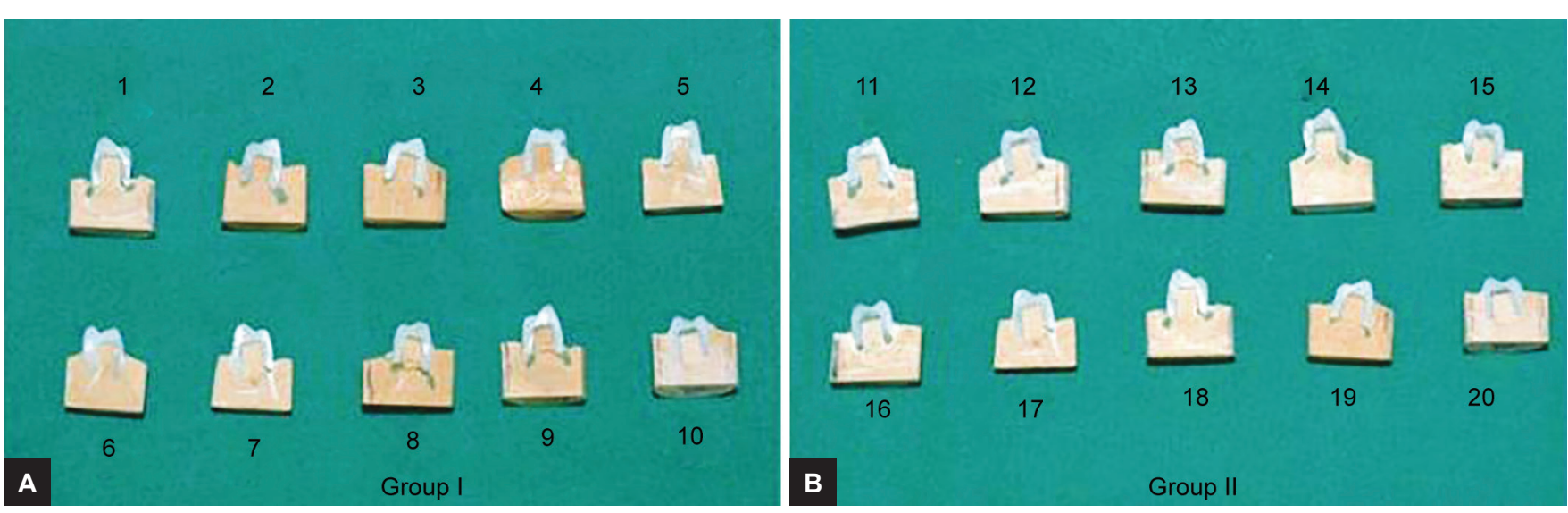

Figs $8 \mathrm{~A}$ and $\mathrm{B}$ : Sectioned zirconia crowns
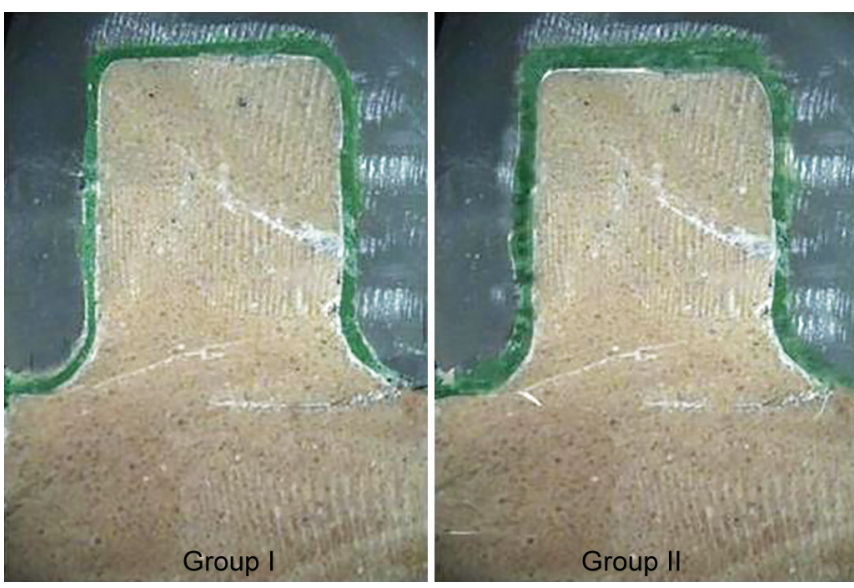

Fig. 9: Stereomicroscopic image

direction into two equal parts (Figs $8 \mathrm{~A}$ and $\mathrm{B}$ ). The midpoint of the buccal and lingual surfaces of the crowns was marked to standardize sectioning. These were observed and photographed under a stereomicroscope (Fig. 9) (Wuzhou New Found Instrument Co. Ltd, China) to visualize the discrepancy in marginal and internal fits.

\section{RESULTS}

\section{Evaluation Parameters}

The images obtained from the stereomicroscope were transferred to the computer, and ImageJ software was used to perform the measurements.

The cement analog thickness was measured in five predetermined regions (Fig. 10)..$^{13}$

1. Marginal fit: Perpendicular measurement from the internal surface of the crown to the margin of the die

2. Chamfer area: $800 \mu \mathrm{m}$ occlusal to the margin of the die

3. Axial wall: Internal adaptation at the midpoint of the axial wall

4. Axio-occlusal transition area: Transition from the occlusal plateau to the axial wall

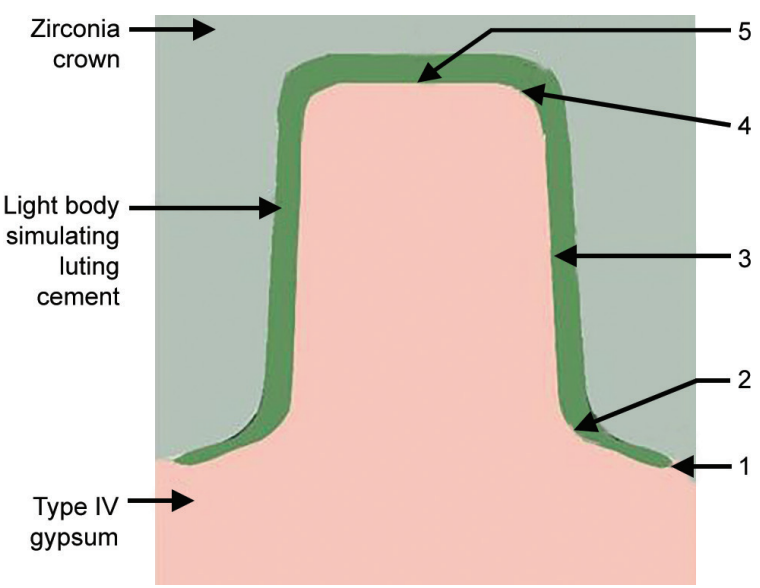

Fig. 10: Schematic representation of the measuring areas of sectioned zirconia crown

5. Occlusal area: $500 \mu \mathrm{m}$ from the axio-occlusal angle in the direction of the center of the occlusal plateau.

Location 1 represents marginal fit and locations 2, 3, 4, and 5 represent internal fit of the crown. ${ }^{14,15}$ All measurements were manually taken, and the measuring locations were standardized to minimize errors.

Selecting appropriate statistical test: In this study, we are examining the effect of scanning methods (independent variable) on the dependent variables. The scores are measured repeatedly twice on each crown. Hence, a paired-samples t-test will be the most appropriate statistical test, provided the assumptions hold (Table 1).

Graphs 1 to 5 reveal that the mean marginal fit and internal fit for indirect method is on the upper side of the scale, whereas the mean for the direct method is on the lower side of the scale for each predetermined region. Thus, the difference in the means of two methods is quite large and is likely to be significant.

In summary, the present data supported the fact that the marginal and internal fit by direct method is statistically different than indirect method at each predetermined region. 
Table 1: Comparative marginal and internal fit evaluation of groups I and II

\begin{tabular}{|c|c|c|c|c|c|c|c|c|c|c|}
\hline \multirow{2}{*}{$\begin{array}{l}\text { Sample } \\
\text { Crown }\end{array}$} & \multicolumn{2}{|c|}{ Marginal fit } & \multicolumn{2}{|c|}{ Chamfer area } & \multicolumn{2}{|c|}{ Axial wall } & \multicolumn{2}{|c|}{ Axio-occlusal angle } & \multicolumn{2}{|c|}{ Occlusal area } \\
\hline & $I$ & II & I & II & $I$ & II & I & II & I & II \\
\hline 1 & 23.65 & 62.92 & 33.32 & 98.43 & 28.82 & 72.62 & 33.78 & 118.59 & 30.85 & 84.51 \\
\hline 2 & 24.04 & 58.21 & 37.63 & 94.42 & 29.54 & 67.84 & 38.36 & 114.52 & 32.43 & 81.28 \\
\hline 3 & 26.97 & 69.43 & 38.21 & 103.44 & 32.61 & 81.42 & 38.43 & 121.83 & 34.56 & 93.32 \\
\hline 4 & 22.45 & 50.04 & 35.67 & 91.60 & 27.68 & 62.84 & 36.40 & 111.77 & 30.21 & 76.84 \\
\hline 5 & 20.68 & 53.26 & 29.80 & 90.40 & 25.71 & 64.55 & 30.30 & 110.49 & 27.84 & 77.04 \\
\hline 6 & 28.76 & 62.26 & 37.32 & 98.34 & 33.04 & 72.28 & 38.23 & 118.53 & 35.62 & 84.97 \\
\hline 7 & 21.90 & 58.95 & 35.78 & 96.56 & 28.76 & 67.97 & 36.78 & 116.46 & 31.48 & 82.57 \\
\hline 8 & 22.53 & 58.97 & 33.57 & 94.68 & 29.81 & 72.44 & 34.97 & 114.56 & 31.69 & 83.26 \\
\hline 9 & 19.80 & 60.23 & 31.78 & 92.68 & 25.57 & 69.29 & 32.90 & 113.83 & 28.36 & 79.82 \\
\hline 10 & 20.84 & 64.56 & 32.56 & 101.63 & 27.82 & 75.57 & 33.69 & 119.62 & 29.63 & 88.34 \\
\hline Mean & 23.16 & 59.88 & 34.56 & 96.22 & 28.94 & 70.68 & 35.48 & 116.02 & 31.27 & 83.20 \\
\hline
\end{tabular}

All values were in micrometer $(\mu \mathrm{m})$; group I: Direct method of scanning; group II: Indirect method of scanning

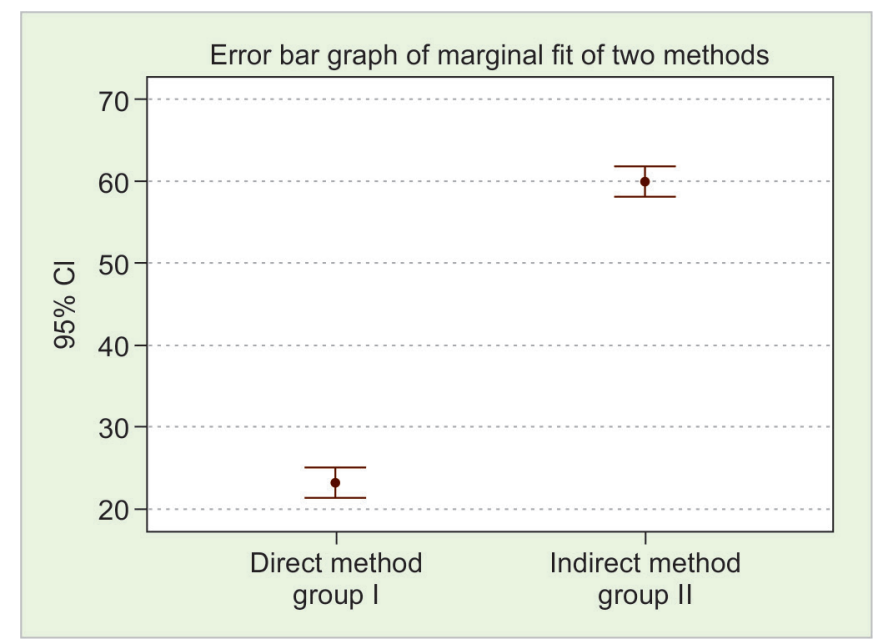

Graph 1: Graph of marginal fit of two methods

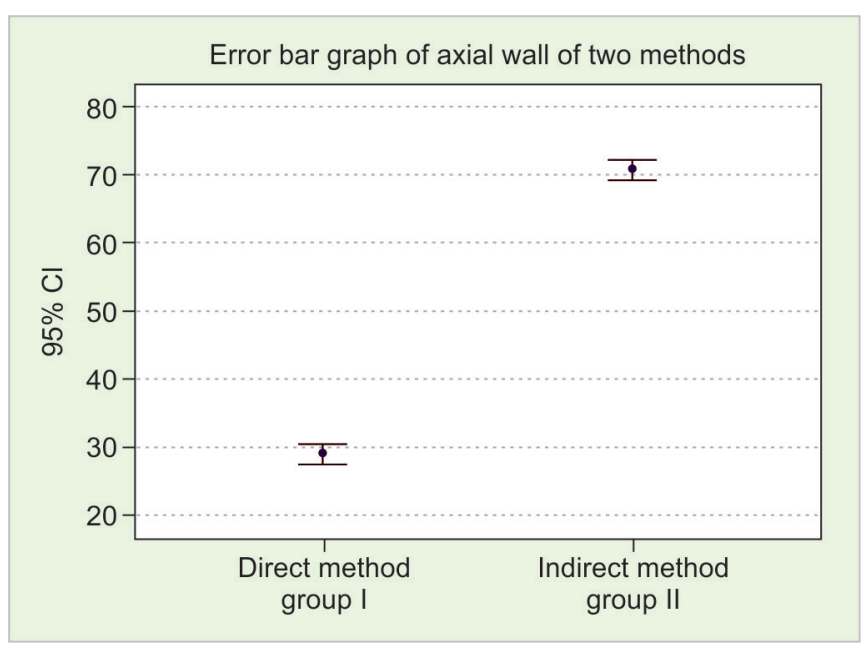

Graph 3: Graph of axial wall of two methods

\section{DISCUSSION}

The marginal and internal fit of restorations is of particular interest and an important quality criterion for evaluation of dental restorations. The presence of marginal and internal discrepancies leads to increased dissolution of

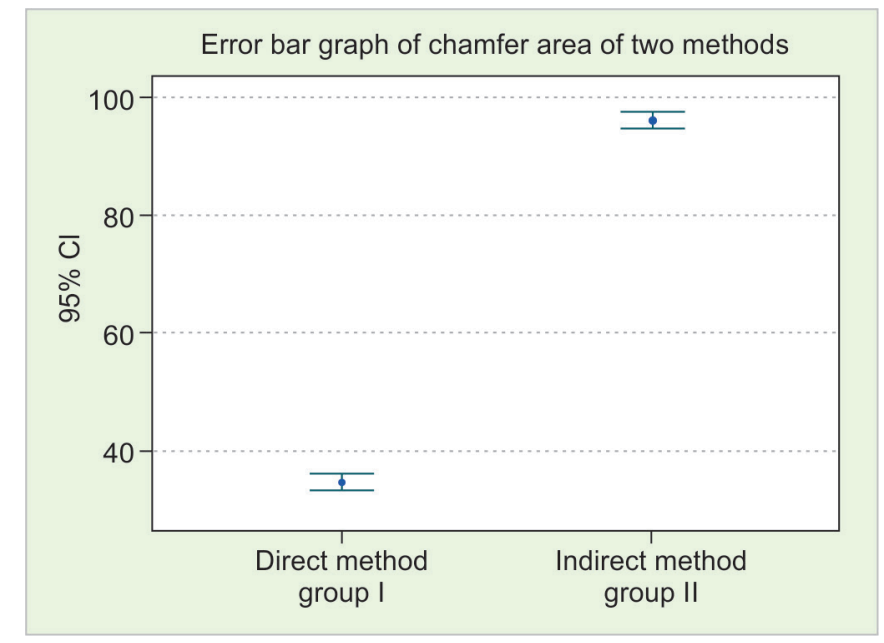

Graph 2: Graph of chamfer area of two methods

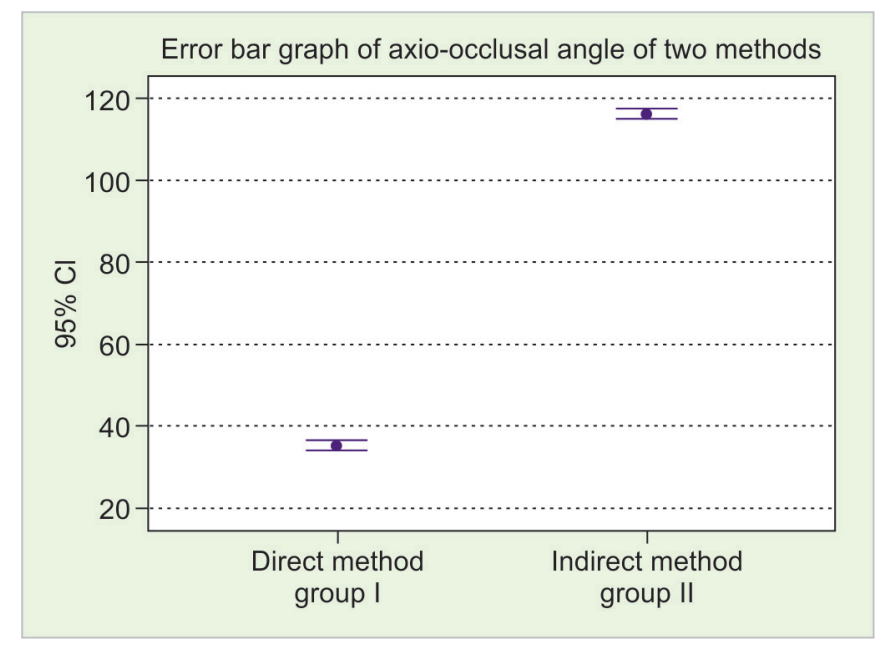

Graph 4: Graph of axio-occlusal angle of two methods

the luting cement, creating an area of biofilm development that leads to caries and periodontal disease, thereby reducing the longevity of restorations.

The accuracy of CAD/CAM restorations depends on the CAD/CAM system and on the materials used. Errors 


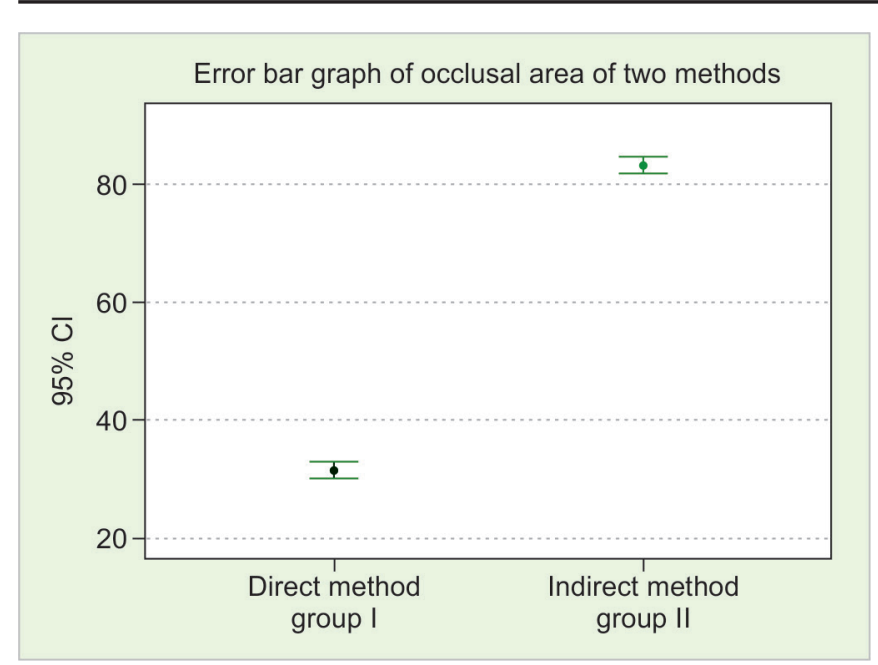

Graph 5: Graph of occlusal area of two methods

may occur in any step of the process chain starting from impression making, extraoral or intraoral digitization via $\mathrm{CAD} / \mathrm{CAM}$ up to final sintering.

Groups I and II presented a similar pattern, larger mean fit values in the axio-occlusal angle followed by occlusal area, chamfer area, axial wall, and marginal fit locations. Reich et $a 1^{16}$ also reported differences in the restoration fit according to the measuring locations. These studies reported an increase in the mean gap values from the marginal area to central measuring locations, suggesting that the adaptation of CAD/ CAM restorations is less accurate in the internal areas.

The crown produced by direct and indirect method showed a significantly lesser fit at the axio-occlusal angle and occlusal area. This finding could be partially explained by limitations in the scanner resolution, which may produce slightly rounded edges. A phenomenon called "point clouds" that occurs during the scanning process could be transformed by the software in an area with internal imperfections that can result in adaptation interferences in both marginal and occlusal areas. The metal model used in this study has a small size, which could generate "point clouds," since smaller the scanned area, the greater the chance of errors in reproducing fine details. ${ }^{17}$

\section{CONCLUSION}

The results did show better marginal and internal fit in crowns fabricated by the direct method; however, the crown fabricated by the indirect method has more discrepancy, but was in the clinically acceptable limit. Both methods can be employed for fabrication of zirconia crowns depending on the operator's preference of carrying out chairside scanning or laboratory scanning.

\section{CLINICAL SIGNIFICANCE}

The result of the present study may serve as a useful guide in deciding which method of scanning would give a better marginal and internal fit of monolithic zirconia crowns fabricated by direct and indirect methods of scanning, so that the longevity of the crowns in clinical situation can be predicted.

\section{REFERENCES}

1. Willer J, Rossbach A, Weber HP. Computer-assisted milling of dental restorations using a new CAD/CAM data acquisition system. J Prosthet Dent 1998 Sep;80(3):346-353.

2. Duret F, Preston JD. CAD/CAM imaging in dentistry. Curr Opin Dent1991 Apr;1(2):150-154.

3. Mörmann WH, Brandestini M, Lutz F, Barbakow F. Chair side computer-aided direct ceramic inlays. Quintessence Int 1989 May;20(5):329-339.

4. Andersson M, Oden A. A new all-ceramic crown: a densesintered, high purity alumina coping with porcelain. Acta Odontol Scand 1993 Feb;51(1):59-64.

5. Beurer F, Naumann M, Gernet W, Sorensen JA. Precison of fit: zirconia three-unit fixed dental prostheses. Clin Oral Investig 2008 Sep;13(3):343-349.

6. Fransson B, Øilo G, Gjeitanger R. The fit of metal-ceramic crowns, a clinical study. Dent Mater 1985 Oct;1(5):197-199.

7. Karlsson S. The fit of Procera titanium crowns. An in vitro and clinical study. Acta Odontol Scand 1993 Jun;51(3):129-134.

8. McLean JW, von Fraunhofer JA. The estimation of cement film by an in vivo technique. Br Dent J 1971 Aug;131(3):107-111.

9. Boening K, Reppel PD, Walter M. Non-cast titanium restorations in fixed prosthodontics. J Oral Rehabil 1992 May;19(3):281-287.

10. Lang NP, Kiel RA, Anderhalden K. Clinical and microbiological effects of subgingival restorations with overhanging or clinically perfect margins. J Clin Periodontol 1983 Nov;10(6):563-578.

11. Valderhaug J, Heloe LA. Oral hygiene in a group of supervised patients with fixed prostheses. J Periodontol 1977 Apr;48(4):221-224.

12. Pallis K, Griggs JA, Woody RD, Guillen GE, Miller AW. Fracture resistance of three all-ceramic restorative systems for posterior applications. J Prosthet Dent 2004 Jun;91(6):561-569.

13. Moldovan O, Luthardt RG, Corcodel N, Rudolph H. Threedimensional fit of CAD/CAM-made zirconia copings. Dent Mater 2011 Dec;27(12):1273-1278.

14. Beuer F, Aggstaller H, Edelhoff D, Gernet W, Sorensen J. Marginal and internal fits of fixed dental prostheses zirconia retainers. Dent Mater 2009 Jan;25(1):94-102.

15. Grenade C, Mainjot A, Vanheusden A. Fit of single tooth zirconia copings: comparison between various manufacturing processes. J Prosthet Dent 2011 Apr;105(4):249-255.

16. Reich S, Wichmann M, Nkenke E, Proeschel P. Clinical fit of all-ceramic three-unit fixed partial dentures, generated with three different CAD/CAM systems. Eur J Oral Sci 2005 Apr;113(2):174-179.

17. Luthardt R, Weber A, Rudolph H, Schone C, Quaas S, Walter M. Design and production of dental prosthetic restorations: basic research on dental CAD/CAM technology. Int J Comput Dent 2002 Apr-Jun;5(2-3):165-176. 